\title{
Socioeducação e Projeto de Vida: relato de oficinas com adolescentes em cumprimento de medida socioeducativa em meio aberto e fechado
}

Georgiano Joaquim Pereira Antônio dos

Santos Centro Universitário Salesiano de São Paulo - UNISAL Lorena, São Paulo, Brasil.

Quintanista do Curso de Psicologia

Bolsista de Iniciação Científica CNPQ

E-mail: georgiano9@hotmail.com

\section{Sônia Maria Ferreira Koehler}

Centro Universitário Salesiano de São Paulo - UNISAL

Psicóloga e Pedagoga. Doutorado em Psicologia do escolar e do desenvolvimento Humano. IPUSP. Coordenadora do Observatório de Violência nas escolas/UNISAL/Lorena

E-mail: soniakoehler@hotmail.com

\section{Jéssica da Sousa Vilela}

Centro Universitário Salesiano de São Paulo - UNISAL

Psicóloga. Mestrado em Psicologia do escolar e do desenvolvimento

Humano. IPUSP.

Vice coordenadora do Observatório de Violência nas escolas/UNISAL/Lorena

E-mail: jessica.sousasv@hotmail.com 


\section{Resumo}

O presente trabalho é um relato de duas oficinas sobre "Projeto de Vida" com adolescentes em medida socioeducativa em meio aberto e em meio fechado, aplicadas por duas instituições do interior do estado de São Paulo. Objetivos: Identificar valores e competências dos adolescentes para a construção de uma trajetória pessoal; propor reflexões sobre o papel de suas escolhas no desenvolvimento de um projeto de vida. Metodologia: Participaram da oficina 20 adolescentes em medida fechada e 9 adolescentes em medida aberta. $\mathrm{O}$ encontro foi dividido em três momentos: introdução do tema; dinâmica reflexão sobre escolhas; discussão e fechamento. Consideração finais: A exposição deste relato teve como intuito demostrar a importância da realização de trabalhos sobre projeto de vida com adolescentes em conflito com a lei, como forma de proporcionar a reflexão e estruturação de um projeto consistente que favoreça o afastamento das "zonas de perigo" em que eles se encontram.

Palavras-chave: Adolescente em conflito com a lei. Medida socioeducativa. Projeto de Vida. Observatório de Violências nas Escolas/UNISAL-Lorena.

\section{Abstract}

The present work is a repport from two workshops about "Life Project" with teenagers placed in socio educational measures in opened and closed environments, applied by two institutions in the interior of the state of São Paulo. Objectives: To identify teenagers' values and skills to develop their life trajectory; to propose reflections about the role of their decisions when it comes to the construction of a life project. Methodology: 20 teenagers in closed socio educational measure and 9 in opened social educational measure took part in the workshop. The meeting was divided into three moments: subject introduction; workshop about the reflection of their choices; discussion and closure. Final considerations: the exposure of this report aimed to show the significance of working life project with teenagers in conflict with the law in order to provide reflection and ways to structure a consistent project that favors the distance between teenagers and "danger zones" which they are in.

Keywords: Teenagers in conflict with the law. Socio educational measure. Life Project. Observatório de Violências nas Escolas/ UNISAL-Lorena. 


\section{Introdução}

O presente relato de experiência deriva de um recorte da pesquisa intitulada "Como socioeducadores compreendem os direitos e deveres de adolescentes em conflito com a lei? ", vinculada ao Observatório de Violências nas Escolas, do Núcleo UNISAL - Lorena/SP, que se constitui em um núcleo de estudos e pesquisas e compõe a Cátedra UNESCO: Juventude, Educação e Sociedade (UCB).

O artigo foi construído a partir do desenvolvimento e vivência de uma oficina de "Projeto de Vida", realizada pelos integrantes do Observatório de Violências nas Escolas ${ }^{1}$ com adolescentes em conflito com a lei em medida socioeducativa em meio aberto e em meio fechado, aplicadas por duas instituições do interior do estado de São Paulo. A oficina foi elaborada com o intuito de identificar valores e competências dos adolescentes para a construção de uma trajetória pessoal, bem como propor reflexões sobre o papel de suas escolhas no desenvolvimento de um projeto de vida.

Sabe-se que, muitas vezes, os adolescentes em conflito com a lei causam incômodo nos ambientes em que se encontram inseridos, pois não se adéquam às regras e acabam por transgredi-las, justamente por não se sentirem integrados ao jogo social. Apesar disso, torna-se necessário perceber que a violência infantojuvenil não pode ser resumida ao simples ato, sendo tratada apenas na via da repressão (seja ela policial ou médica), mas sim como uma questão social (LEVISKY, 1998), na qual se deve lançar um olhar multidisciplinar com o caráter preventivo e educacional, pois, como aponta Levisky (2000, p. 32), a "delinquência pode ser a resultante de uma construção social cuja raiz está na própria violência familiar e social".

Nessa perspectiva, a realização de trabalhos que contribuam para que adolescentes em conflito com a lei possam participar de atividades que possibilitem repensar suas práticas sociais e assumir o papel de cidadãos de direitos e deveres torna-se de grande valia para uma possível reinserção destes na sociedade.

\section{Fundamentação Teórica}

\section{Um novo olhar sobre a infância e adolescência: o Estatuto da Criança e do Adolescente (ECA)}

A promulgação do Estatuto da Criança e do Adolescente proporcionou um novo olhar referente à criança e ao adolescente, entendendo-os como pessoas em situação peculiar de desenvolvimento, independentemente de qualquer outra

\footnotetext{
${ }^{1}$ Os integrantes do Observatório de Violências nas Escolas foram mediadores dessa oficina.
} 
variável presente. A desconstrução do estigma do "menor" tem início no Brasil, em âmbito de legislação, a partir da Constituição Federal de 1988, sendo reforçado e estruturado com a promulgação do ECA. Deixar de nomear a infância pobre e a que se encontra em conflito com a lei de "menor" não se resume a um simples movimento de troca de nomenclatura, mas sim a uma grande revolução contra uma carga "ideológica, repleta de valores e preconceitos" (BLAY, 2000, p. 35) presentes neste conceito.

Com o ECA acaba-se com a ideia de que a criança e o adolescente são simples objetos do processo, estes agora passam a ser enquadrados na condição de sujeitos de direito (SARAIVA, 2002; LIBERATI, 2010), entendidos como cidadãos que possuem direitos e deveres constitucionalmente consagrados, ocorrendo a modificação da situação de "menor" para criança e adolescente cidadão (FERREIRA, 2008).

Entendendo a criança e o adolescente como cidadãos, o ECA ressalta - com outra roupagem - o que já se encontra na Constituição Federal, que todo cidadão possui determinados direitos e deveres, e ainda que, caso estes sejam violados ou não cumpridos, tanto pela sociedade ou Estado, família e pela própria criança ou adolescente, será passível de uma medida de intervenção (BRASIL, 1990).

Ao estabelecer que a criança e o adolescente são pessoas em situação peculiar de desenvolvimento, o ECA não os coloca em uma posição privilegiada, como sendo "intocáveis pela Lei", pelo contrário, o Estatuto cria diretrizes coerentes para o trato desses cidadãos, fugindo dos absurdos propagados por legislações anteriores. A partir do ECA ocorre uma inovação na legislação referente à criança e ao adolescente, com o fim das ambiguidades existentes em legislações anteriores destinadas a este público, consolidando, assim, a responsabilidade penal no âmbito judicial e a proteção no âmbito social destes indivíduos.

Independentemente da criança ou adolescente terem cometido ato infracional, o ECA, em seu artigo $5^{\circ}$, garante que:

Nenhuma criança ou adolescente será objeto de qualquer forma de negligência, discriminação, exploração, violência, crueldade e opressão, punido na forma da lei qualquer atentado, por ação ou omissão, aos seus direitos fundamentais (BRASIL, 1990, s/p).

Além do mais, o ECA, em seus artigos, afasta-se de concepções de caráter retribucionista e paternalista, não propagando a ideia de "quanto maior a infração maior a punição", assim como não isenta o adolescente autor de ato infracional de responsabilização pela infração cometida (ALEXANDRE, BARCELOS, 2007). Em seu artigo 18, o ECA preconiza que é "dever de todos velar pela dignidade da criança e do adolescente, pondo-os a salvo de qualquer 
tratamento desumano, violento, aterrorizante, vexatório ou constrangedor" (BRASIL, 1990).

A personificação desse posicionamento encontra-se nas medidas de proteção que são definidas por Sêda (1990 apud LIBERATI, 2010, p. 98) como "providencias adotas por autoridades com poderes especiais sempre que crianças e adolescentes, caso a caso, forem ameaçados ou violados em seus direitos". Segundo o ECA, de acordo com o art. 98:

As medidas de proteção à criança e ao adolescente são aplicáveis sempre que os direitos reconhecidos neste Lei forem ameaçados ou violados: I - por ação ou omissão da sociedade ou do Estado; II - por falta, omissão ou abuso dos pais ou responsáveis; III - em razão de sua conduta.

Percebe-se que o próprio ECA, em seu art. 98, inciso III, explicita que a própria criança ou adolescente poderá vir a ameaçar ou violar seus próprios direitos, sendo, dessa forma, passível de intervenção. Deve-se ressaltar que a aplicação dessas medidas deverá levar em consideração, de acordo com o art. 100, “[...] as necessidades pedagógicas, preferindo-se aquelas que visem ao fortalecimento dos vínculos familiares". Caso seja verificada qualquer das hipóteses prevista no art. 98, a autoridade competente poderá determinar as seguintes medidas:

Art. 101. I - encaminhamento aos pais ou responsáveis, mediante termo de responsabilidade; II - orientação, apoio e acompanhamento temporários; III - matrícula e frequência obrigatória em estabelecimento oficial de ensino fundamental; IV - inclusão em programa comunitário ou oficial de auxílio à família, à criança e ao adolescente; V - requisição de tratamento médico, psicológico ou psiquiátrico, em regime hospitalar ou ambulatório; VI - inclusão em programa oficial ou comunitário de auxílio, orientação e tratamento a alcoólatras e toxicômanos; VII - acolhimento familiar; IX - colocação em família substitutiva (BRASIL, 1990, s/n).

Em alguns casos, este comportamento poderá estar relacionado a prática do ato infracional, o qual, consequentemente, resultará em uma ação judiciária ou tutelar que terá como efeito a imposição de uma medida protetiva adequada ao caso. A aplicação destas medidas terá como finalidade a proteção dos direitos destes adolescentes, evitando, assim, prejuízos aos direitos garantidos pelo Estatuto (LIBERATI, 2010). De acordo com o art. 105, em caso de ato infracional praticado por criança será colocado em prática as medidas previstas no art. 101. No caso de adolescente autor de ato infracional será aplicado as medidas previstas no art. 112 do Estatuto: 
Verificada a prática de ato infracional, a autoridade competente poderá aplicar ao adolescente as seguintes medidas: I. advertência; II. Obrigação de reparar o dano; III. Prestação de serviços à comunidade; IV. Liberdade assistida; V. inserção em regime de semi-liberdade; VI. Internação em estabelecimento educacional; VII - Qualquer uma prevista no art. 101, I a VI (BRASIL, 1990, s/p).

No que tange o ato infracional, este é entendido, conforme postula o ECA em seu art. 103 como uma "conduta descrita como crime ou contravenção penal". Assim, qualquer ação que seja categorizada como ato ilícito, como crime ou contravenção penal a partir do Código Penal quando praticada por uma criança ou adolescente terá caráter de ato infracional.

Essa diferenciação se dá justamente pelo fato de a imputabilidade penal ser fixada em 18 anos, conforme é estabelecido pelo art. 228 da Constituição Federal, assim como pelo art. 104 do Estatuto da Criança e do Adolescente que considerada "penalmente inimputáveis os menores de dezoito anos, sujeito às medidas previstas pela Lei".

Segundo Saraiva (2009), não podemos confundir inimputabilidade penal com impunidade, o que, infelizmente, ainda ocorre. Essa confusão se dá justamente pelo desconhecimento do sistema de responsabilidade penal juvenil contemplado pelo ECA. Pode-se citar como reflexo disso o crescimento de movimento a favor da redução da maioridade penal, por exemplo.

\section{Compreendendo o adolescente autor de ato infracional}

Para compreender o adolescente em conflito com a lei, é necessário compreender a adolescência como fenômeno psicossocial, compreendida em contexto amplo, não como uma condição posta, mas sim como uma "perspectiva de história de vida, de criação de vínculos, de possibilidades, de oportunidades, de características pessoais, individuais e relacionais" (AMORIM, 2008. p. 37) que acontecem a partir de um grande escopo estrutural, o qual compreende as "questões de classe social, gênero, etnia, cultura, momento histórico e particularidades da história de cada um" (ibidem).

Quanto a isso, Emilio Garcia Mendez (1998 apud SARAIVA, 2002, s/p) em relação ao panorama latino-americano, exalta a existência de dois tipos de infância, sendo "uma minoria com as necessidades básicas amplamente satisfeitas (crianças e adolescentes) e uma maioria com suas necessidades básicas total ou parcialmente insatisfeitas (os menores)". Levisky (1998) ainda nos mostra como a globalização em conjunto com o poderio econômico e midiático exercem uma grande influência e controle sobre a mente humana, fatores que estão diretamente ligados a inúmeras problemáticas presentes nos dias atuais e, evidentemente, também serão parte integrante da delinquência juvenil. 
Esses fatores aliados a exclusão de diversas ordens - socioeconômica, de gênero, de raça etc - que a própria sociedade produz e reproduz, ativará o que Marin (1998) denominará de violência aniquiladora, "no sentido de se ir ao ato para a satisfação das necessidades, através de uma descarga imediata" (MARIN, 1998, p. 84). Dessa forma, a prática do ato infracional, não sem exceções, pode ser entendida como a personificação dessa violência aniquiladora, numa perspectiva psicanalítica. Essa violência em ato, ou experiência em excesso é caracterizada por Marin como:

[...] uma situação na qual o outro é destruído por não poder existir de modo algum, em que não se constitui alteridade e impera o princípio absoluto do Um. Estou me referindo ao sujeito que se vê absolutamente ameaçado, com riscos de esfacelamento e desmoronamento, que precisa apagar qualquer vestígio do outro que por algum motivo o ameace, o excite, convoque-o ou represente aspectos seus renegados que não quer enfrentar. Ou então, quando o outro visto como "estrangeiro", que provoca inquietamente estranheza, é insuportável e precisa ser eliminado; ou ainda quando o sujeito considera o outro apenas a serviço de garantir o seu próprio gozo, rompendo as barreiras dos organizadores sociais e das leis. (MARIN 2002, p. 77-78)

A condição de pessoa em desenvolvimento de crianças e adolescentes faz com que estes estejam vulneráveis e receptivos à pressões internas e externas que interferiram de algum modo na formação de sua identidade. Assim, para compreender os motivos que levam algum adolescente a inflacionar, é necessário assumir uma perspectiva biopsicossocial e se afastar de resposta de caráter apenas culpabilizante, pois a problemática do ato infracional é muito mais ampla do que apenas a culpa individual e pessoal (AMORIM, 2008).

Winnicott (1956) nos mostra que a violência empregada pela criança ou jovem, muitas vezes, faz parte de um movimento de esperança, que possui como meta a busca por algo bom que foi perdido. Esse movimento se iniciaria a partir de uma deprivação ${ }^{2}$ que forçaria excessivamente as defesas disponíveis. Para se

\footnotetext{
${ }^{2}$ De acordo com Maia e cols.: "A base da tendência antissocial resulta de uma experiência inicial boa que foi perdida e o aspecto essencial desta é a criança ter alcançado a capacidade de perceber que a causa do desastre foi devida a uma falha do ambiente. Isso provoca a distorção da personalidade e o impulso de buscar a cura numa nova provisão ambiental. A esse processo de desapossamento, Winnicott (1987) denominará deprivação, e marcará a diferença entre essa situação e a de privação, ou seja, uma situação na qual a criança nunca teve nada, e por isso não perde coisa alguma mais tarde, diferente da situação das crianças que estamos chamando de antissociais" (2007, p. 336).
} 
levar em consideração a deprivação deve-se supor que a criança possuiu inicialmente uma experiência de confiabilidade ambiental, podendo desta forma "contar" com o ambiente, o que, posteriormente, foi perdido de forma repentina (DIAS, 2011). Em um ambiente satisfatório, com cuidados satisfatórios e a presença de figuras adultas de referência, a criança e o adolescente encontram condições de desenvolver um consistente "ambiente interno", que o auxiliará na construção de limites. Na falta disso, a necessidade de uma intervenção externa, ou seja, de alguém que olhe para ele se mostra presente (AMORIM, 2008).

Assim, a tendência antissocial compilará o meio a ser importante, a reconhecer sua falha com este indivíduo. Desse modo, a criança ou jovem antissocial buscaria, através do roubo, da mentira ou de atitudes violentas, o reconhecimento da falha ambiental e a reconstrução da estrutura rompida (WINNICOTT, 1961).

Dessa forma, a violência infanto-juvenil não pode ser resumida ao simples ato, sendo tratada apenas na via da repressão (seja ela policial ou médica), mas sim como uma questão social na qual se deve lançar um olhar multidisciplinar com o caráter preventivo e educacional, pois como aponta Levisky (2000, p. 32) a "delinquência pode ser a resultante de uma construção social cuja raiz está na própria violência familiar e social". Nesta perspectiva, a socioeducação deve superar o caráter repressivo de legislações anteriores e proporcionar o que já se encontra em lei: "a preparação do jovem para o convívio social" (BRASIL, SEDH, 2006, p. 14), respeitando-o, levando em consideração seu caráter de vulnerabilidade e sua singularidade.

\section{Atendimento socioeducativo}

Para compreender o panorama da organização do atendimento socioeducativo no Brasil, torna-se necessário, primeiramente, visualizar o atendimento à criança e ao adolescente como um todo. Sobre esse ponto, de acordo com o ECA a "política de atendimento dos direitos da criança e do adolescente far-se-á através de um conjunto articulado de ações governamentais e não governamentais, da união, dos Estados, do Distrito Federal e dos Municípios (BRASIL, 1990, art. 86).

Dessa forma, o ECA, em 1990, reiterava o que se encontrava previsto na Constituição Federal de 1988, ou seja, a união entre as três esferas de governo, como também da população civil, para a implantação e efetivação das ações destinadas em favor da população infantojuvenil (Políticas Sociais Básicas, Políticas de Proteção Especial e Políticas Socioeducativas), o que será reafirmado em seu artigo 88. 
Essa divisão de responsabilidades "pressupõe a existência de uma rede de serviços, em que a responsabilidade é compartilhada pelos diferentes entes políticos" (ILANUD, 2004, p. 16), assim, define-se competências exclusivas desses segmentos que são seguidas por "competências concorrentes que não só podem como devem ser compartilhadas pelos estados, municípios e União" (ILANUD, 2004, p. 16). Vale ressaltar que o SINASE, em 2006, reafirmará esse pressuposto.

Seguindo essas diretrizes norteadoras, após a aprovação da Resolução no 109/2009 do Conselho Nacional de Assistência Social que aprovou a Tipificação Nacional de Serviços Socioassistenciais, o estado de São Paulo inicia, em 2009, o processo de municipalização dos serviços de medida socioeducativa em meio aberto. Desse modo, o serviço até então de responsabilidade da Fundação Centro de Atendimento Socioeducativo ao Adolescente (CASA), passa a ser de competência da Secretaria de Desenvolvimento Social.

A partir disso, a execução dessas medidas começa a ser realizada "diretamente pela equipe dos Centros Especializados de Assistência Social (CREAS) ou por organizações não governamentais (ONGs), situação na qual o serviço é terceirizado" (RESOLUÇÃO 130/2005 citada por MORAIS, MAFITANO, 2014, p. 615). Segundo o Instituto Latino Americano das Nações Unidas para Prevenção do Delito e Tratamento do Delinquente - Brasil (ILANUD, 2004) a justificativa para essa reordenação reside no reconhecimento que a reinserção social do jovem se torna mais possível quando este não é retirado da sua esfera local e comunitária.

\section{Sistema Nacional de Atendimento Socioeducativo (SINASE)}

Ao se levar em consideração o passado histórico das legislações brasileiras no que se refere aos adolescentes em conflito com a lei, o SINASE apresenta-se como uma sistematização necessária do atendimento socioeducativo, objetivando evitar a culpabilização e criminalização a adolescentes que foram expostos anteriormente.

Conforme texto do $\operatorname{CONANDA}^{3}$ (2006) a criação do SINASE provém da:

[...] necessidade de se constituir parâmetros mais objetivos e procedimentos mais justos que evitem ou limitem a discricionariedade, o SINASE reafirma a diretriz do Estatuto sobre a natureza pedagógica da medida socioeducativa. Para tanto, este sistema tem como plataforma inspiradora os acordos internacionais sob diretos humanos dos quais o Brasil é

\footnotetext{
${ }^{3}$ CONANDA. Cf. http://dh.sdh.gov.br/download/resolucoes-conanda/res-160.pdf
} 
signatário, em especial na área dos direitos da criança e do adolescente (BRASIL, 2006, p. 13).

De acordo com a lei $n^{0}$ 12.594/124, em seu artigo 1ํㅡ, o Sistema Nacional de Atendimento Socioeducativo (SINASE) é:

[...] o conjunto ordenado de princípios, regras e critérios que envolvem a execução de medidas socioeducativas, incluindo-se nele, por adesão, os sistemas estaduais, distrital e municipais, bem como todos os planos, políticas e programas específicos de atendimento a adolescente em conflito com a lei.

A implantação da Lei do SINASE acompanha o desafio de articulação de um sistema integrado "entre as esferas governamentais, o Sistema de Justiça e as políticas setoriais básicas como Assistência Social, Saúde, Educação, Cultura, Esporte, entre outras" (SINASE, 2015, p. 65) como forma de garantia da efetividade e eficácia na execução das medidas socioeducativas.

Além disso, tornou obrigatória a criação e implementação de uma política de atendimento compartilhada entre as esferas governamentais (federal, estadual e municipal), sendo isso realizado através dos Planos Decenais de Atendimento Socioeducativo como também pela oferta de serviços e programas destinados ao atendimento socioeducativo. Esta obrigatoriedade de compartilhamento possui como intuito a descentralização da responsabilidade referente ao atendimento socioeducativo, dando diretrizes específicas a serem cumpridas por cada esfera governamental.

No cenário atual, em relação ao Plano Decenal, foi aprovado em 2013, pela resolução 160 do CONANDA, o Plano Nacional de atendimento Socioeducativo, com metas a serem executadas em 10 anos, ou seja, entre 2013 e 2022, "visando à reordenação e aperfeiçoamento do atendimento socioeducativo no Brasil" (SINASE, 2015, p. 66). Agora o desafio se encontra na elaboração dos planos estaduais e municipais para que a articulação entre as esferas governamentais funcione e, consequentemente, ocorra um melhoramento no atendimento socioeducativo.

\section{Socioeducação e medidas socioeducativas em meio fechado}

No que se refere às medidas socioeducativas em meio fechado, o ECA, em seu artigo 112, postula que as medidas que podem ser aplicadas são: $V$. inserção em regime de semiliberdade; VI. Internação em estabelecimento educacional. A aplicação dessas medidas fica a cargo dos governos dos estados da federação e, no caso de São Paulo, a instituição que assume a execução dessas medidas é a Fundação

\footnotetext{
${ }^{4}$ Lei no 12.594 , de 18 de janeiro de 2012. Cf. http://www.planalto.gov.br/ccivil_03/_ato20112014/2012/lei/112594.htm.
} 
CASA. A regionalização do atendimento ocorreu a fim de "garantir o direito à convivência familiar e comunitária dos adolescentes internos, bem como as especificidades culturais" (SINASE, 2006, p. 13).

O Regimento Interno ${ }^{5}$ da Fundação CASA, na disposição dos art. 15 e 17, prevê uma série de direitos e deveres a serem respeitados e cumpridos enquanto o adolescente infrator estiver em cumprimento de medida socioeducativa na Fundação. De acordo com o art. 14 deste Regimento, ao adolescente será assegurada "a mínima intervenção, restrita ao necessário para a realização dos objetivos da medida, além de todos os direitos não atingidos pela sentença ou pela Lei, sem distinção de natureza racial, social, religiosa, política, ou relativa a orientação sexual".

A partir dessa reestruturação, definiu-se a missão, valores e a visão que norteariam o novo sistema. Segunda a própria Fundação CASA ${ }^{6}$, a instituição possui como missão, isto é, como propósito de sua existência:

Executar direta ou indiretamente as medidas sócio educativas, com eficiência, eficácia e efetividade, garantindo os direitos previstos em lei e contribuindo para o retorno dos adolescentes ao convívio social como protagonista de sua história.

Os valores ou atributos tidos como importantes pela instituição pautamse nos princípios de “Justiça, Ética e Respeito ao Ser Humano", visando:

Tornar-se referência no atendimento ao adolescente autor do ato infracional, pautando-se na humanização, personalização, descentralização da execução das medidas socioeducativas, a uniformidade, controle e avaliação das ações e na valorização do servidor (FUNDAÇÃO CASA, s/p).

Alinhada a esses princípios, a medida socioeducativa de internação e semi-internacão, em sua concepção básica, deve possuir um caráter sancionatório e não punitivo, assim como um caráter sociopedagógico, devendo garantir, além dos direitos previstos no ECA, o desenvolvimento de ações educativas, visando à formação da cidadania (BRASIL, SINASE, 2006). Dessa forma, a medida socioeducativa deve direcionar-se à responsabilização do adolescente pelas consequências geradas pelo cometimento do ato infracional, ficando a cargo do Estado a responsabilidade de garantir, no momento de aplicação da medida de

\footnotetext{
${ }^{5}$ Portaria Normativa $n^{\circ} 224 / 2012$.

${ }^{6}$ Fundação CASA. Cf: http://www.fundacaocasa.sp.gov.br/View.aspx?title=miss\%C3\%A3ovis $\%$ C3\%A3o-e-valores\&d=81
} 
restrição de liberdade, acesso à educação, profissionalização e acompanhamento psicossocial para os adolescentes em internação (BRASIL, CNJ, 2012).

De acordo com o artigo 121, §2⿳⺈, do ECA, as unidades de internação em conjunto com a autoridade judiciária responsável pelo acompanhamento da execução da medida, devem estabelecer o prazo para avaliação da medida em até 6 meses quando deverá ser encaminhado o relatório psicossocial do adolescente, incluindo referências sobre o Plano Individual de Atendimento (PIA) desenvolvido durante o cumprimento da medida, o qual deverá ser estruturado a partir das etapas da própria evolução do atendimento, com o objetivo de proporciona o ingresso do adolescente no contexto da vida social, especialmente estudantil e profissional. Para o sucesso do atendimento é necessário a existência de uma equipe técnica multiprofissional.

\section{Socioeducação e medida socioeducativa em meio aberto}

Conforme prescreve o ECA no artigo 112, são consideradas medidas socioeducativa sem privação de liberdade: I - advertência; II - obrigação de reparar o dano; III - prestação de serviços à comunidade (PSC); IV - liberdade assistida (LA); sendo as duas últimas consideradas medidas socioeducativas de meio aberto.

Segundo o Centro de Defesa dos Direitos da Criança e do Adolescente (CEDEDICA, 2009, s/p.), o adolescente submetido à medida socioeducativa em meio aberto "deverá ser acompanhado em seu processo de formação e educação" pelos órgãos municipais "executores das medidas socioeducativas em meio aberto" e, onde não existam os devidos programas, deverá ser designada pelo Poder Judiciário, através do Juizado da Infância e Juventude, pessoa capacitada para o seu acompanhamento.

O serviço executado por esses estabelecimentos deverá contribuir para o acesso aos direitos preconizados pelo ECA e por outras normas, como também para a "ressignificação de valores na vida pessoal e social dos adolescentes e jovens" (PLANO MUNICIPAL DE MEDIDAS SOCIOEDUCATIVA EM MEIO ABERTO DE ARAÇATUBA, 2017, p. 26).

A medida socioeducativa de Prestação de Serviços à Comunidade (PSC) consiste:

[...] na realização de tarefas gratuitas de interesse geral, por período não excedente a seis meses, junto a entidades assistenciais, hospitais, escolas e outros estabelecimentos congêneres, bem como em programas comunitários ou governamentais. Parágrafo único. As tarefas serão atribuídas conforme as aptidões do adolescente, devendo ser cumpridas durante jornada máxima de oito horas semanais, aos sábados, domingos e feriados, ou em dias úteis, de modo a não prejudicar 
a frequência à escola ou à jornada normal de trabalho (BRASIL, 1990, art. 117, s/p).

Destaca-se que as atividades exercidas pelo adolescente, em cumprimento de PSC, não devem ser realizadas em estabelecimentos de iniciativa privada com fins lucrativos (TAVARES, 2012). Assim, a PSC, tem por objetivo a valorização da vida social e comunitária e a responsabilização do adolescente infrator, sem denegri-lo ou constrangê-lo, não podendo, em hipótese alguma, assumir o papel de punição ou trabalhos forçados (PLANO MUNICIPAL DE MEDIDAS SOCIOEDUCATIVA EM MEIO ABERTO DE ARAÇATUBA, 2017).

A medida socioeducativa de Liberdade Assistida (LA) será adotada:

[...] sempre que se afigure a medida mais adequada para o fim de acompanhar, auxiliar e orientar o adolescente. $\S^{-0} \mathrm{~A}$ autoridade designará pessoa capacitada para acompanhar o caso, a qual poderá ser recomendada por entidade ou programa de atendimento. $\$ 2^{\circ}$ A liberdade assistida será fixada pelo prazo mínimo de seis meses, podendo a qualquer tempo ser prorrogada, revogada ou substituída por outra medida, ouvido o orientador, o Ministério Público e o defensor (BRASIL, 1990 art. $118, \mathrm{~s} / \mathrm{p})$.

Essa medida terá por finalidade o estabelecimento de um processo de acompanhamento, auxílio e orientação ao adolescente. Logo, a intervenção e ação socioeducativa devem ser estruturadas com ênfase na promoção da vida social deste (família, escola, trabalho, profissionalização e comunidade) como forma de possibilitar "o estabelecimento de relações positiva" que será a "base de sustentação do processo de inclusão social a qual se objetiva" (BRASIL, SINASE, 2006, p. 44). Assim, o programa assume o papel "catalisador da integração e inclusão social desse adolescente e sua família" (BRASIL, SINASE, 2006, p. 44).

Para a operacionalização desses serviços, é de extrema importância a elaboração do PIA, este deverá conter os objetivos e metas a serem alcançados no decorrer da mediada, tal como perspectivas futuras, sempre levando em consideração as necessidade e interesses do adolescente. Salienta-se que sua construção decorrerá da participação da família, do adolescente e outros atores sociais (BRASIL, SINASE, 2006).

\section{Metodologia}

A equipe do Observatório de Violências nas Escolas foi convidada a desenvolver um trabalho com o tema Projeto de Vida em duas instituições que 
atendem adolescentes em conflito com a lei. Por se tratar de um relato de experiência de uma oficina realizada em instituições distintas e, consequentemente, com públicos diferentes e que possuem suas especificidades, apresentaremos os próximos itens diferenciando as instituições da seguinte forma:

$\checkmark$ Instituição de cumprimento de medida socioeducativa em meio aberto, representada pela sigla (MA);

$\checkmark$ Instituição de cumprimento de medida socioeducativa em meio fechado, representada pela sigla $(\mathrm{MF})$.

As siglas MA e MF serão utilizadas ao longo do texto que se segue.

\section{Local e periodicidade da atividade}

MA: Instituição do terceiro setor no interior do estado de São Paulo responsável pela aplicação de medidas socioeducativas em meio aberto de Liberdade Assistida (LA) e Prestação de Serviços à Comunidade (PSC). A oficina foi aplicada em apenas um encontro.

MF: Instituição estadual de aplicação de medida socioeducativa de internação que atende adolescentes do sexo masculino em conflito com a lei. Inicialmente, a oficina foi estruturada para acontecer em dois encontros, com possibilidade de extensão. Entretanto, devido a questões institucionais, apenas um encontro, com duração de duas horas, foi realizado.

\section{Participantes}

MA: Participaram da oficina 20 (vinte) adolescentes escolhidos pela instituição;

MF: Participaram da oficina 9 (nove) adolescentes escolhidos pela instituição.

\section{Procedimentos}

O encontro foi dividido em três momentos:

1) Sensibilização do grupo e introdução do tema: Consistiu no sorteio de figuras (criança, adolescente, adulto, idoso) e datas que remetiam a algum período (1500, 2000, 1995 etc.), a partir das quais os participantes evocariam lembranças e sentimentos;

2) Dinâmica Viagem de Barco - reflexão sobre escolhas: Consistiu em elencar dez elementos (objetos, sentimentos, pessoas etc.) para levar em uma viagem da qual não haveria volta. Nessa viagem ocorreriam imprevistos e os "tripulantes" deveriam se desfazer de alguns pertences para que o barco chegasse ao seu destino. Ao final sobraria apenas um;

3) Discussão e fechamento 


\section{Materiais}

Os materiais utilizados foram: folha sulfite, material gráfico, lápis, apontador e borracha.

\section{Objetivos}

Ao considerar o público atendido - adolescentes -, a realização dessas oficinas teve como objetivos gerais:

a) Identificar valores e competências dos adolescentes para a construção de uma trajetória pessoal;

b) Refletir sobre as escolhas e o papel delas no desenvolvimento de um projeto de vida.

\section{Resultados e discussão}

As oficinas foram idealizadas como uma possibilidade de reflexão sobre a identidade do adolescente em conflito com a lei, entendendo-os como sujeitos de direitos e deveres, com potencialidades e competências, conforme perspectiva adotada por todos os principais documentos que norteiam a socioeducação, ou seja, o ECA e o SINASE.

\section{Medida aberta e fechada: aproximações e distanciamentos}

A aplicação da mesma oficina em contextos diferentes, isto é, em instituições de medida aberta (MA) e medida fechada (MF) nos proporcionou verificar in loco as especificidades de cada medida. No que se refere aos ambientes nos quais estas foram aplicadas, o aspecto físico e estrutural da MF nos deixa a sensação de que o caráter prisional ainda se encontra muito presente, pois o que se vê são janelas e portas gradeadas, baixa iluminação e odor forte de água sanitária, além, é claro, dos inúmeros agentes socioeducativos responsáveis por vigiar os adolescentes em cumprimento de medida. Situação diferente é encontrada na MA, na qual observa-se um ambiente mais leve, sem grades e agentes socioeducativos, um local aberto e arborizado.

De acordo com o Conselho Nacional do Ministério Público (CNMP), em seu Relatório da Infância e Juventude, o cumprimento das medidas socioeducativas - em especial as medidas restritivas de internação e semiliberdade - estão longe do modelo proposto pelo ECA pelo fato de que "os espaços que deveriam ser de ressocialização mais se assemelham a presídios e penitenciárias, com altos índices de superlotação, em alguns Estados, e 
pouquíssimas oportunidades de formação educacional e profissional" (BRASIL, CNMP, 2015, p. 13).

Citar essas diferenças torna-se importante pois esse ambiente interferirá, consequentemente, no modo em que os adolescentes se apresentam ou não ao outro, bem como se sentem ou não essas instituições como protetoras ou violadoras de direitos. Ao assumir a perspectiva winnicottiana, entendemos que o adolescente em conflito com a lei, não sem exceções, busca algo que foi perdido, um ambiente que repare as deprivações sofridas em algum ponto do desenvolvimento (WINNICOTT, 1956, 1961; DIAS, 2011).

Assim, as instituições socioeducativas, ao assumirem a perspectiva de reinserção desse adolescente na sociedade, devem ter não apenas uma equipe técnica adequada, menos punitiva e mais cuidadora/orientadora, como também devem repensar seus espaços arquitetônicos, os quais devem abandonar o espectro de prisão para assumir um outro, o de acolhimento.

Percebeu-se que, de início, os adolescentes de MF demonstraram resistência em participar e interagir com os mediadores, como se assumissem para si o estereótipo do "menor", do "bandido". Constatou-se esse fato a partir das brincadeiras referentes às tatuagens de palhaço (e sua simbologia) ${ }^{7}$ e a postura rígida e distante assumida inicialmente por eles. Enquanto isso, os adolescentes de MA, apesar de certa resistência inicial, conseguiram estabelecer contato com os mediadores de forma mais rápida, o agir destes, isto é, a forma de se expressar, era menos estereotipada, mais livre, em comparação aos primeiros.

Não se pode esquecer que o estigma do "menor" possui uma carga ideológica, repleta de preconceitos e valores (BLAY, 2000). Nota-se que o adolescente em conflito com a lei também é influenciado e incorpora os estigmas dessa acunha ouvida tão frequentemente por eles. Além disso, o estigma do menor também realiza uma divisão entre infância e adolescência que possui suas necessidades básicas atendidas - o adolescente conhecido, do nosso bairro, amigo do meu ou do seu filho - e a outra com suas necessidades básicas total ou parcialmente insatisfeitas - os menores, o delinquente, o marginal, $\mathrm{O}$ desconhecido (MAIA et al, 2007; MENDEZ, 2008) - a qual muitas vezes o adolescente em conflito com a lei se identifica.

Apesar disso, observou-se uma maior facilidade no desenvolvimento da oficina com os adolescentes em MF em comparação aos de MA. Esse fato pode se relacionar a própria estrutura de encarceramento a qual os primeiros estão submetidos, não existindo a possibilidade de não participarem das atividades propostas - mesmo que essa escolha tenha sido dada pelos mediadores - como ${ }^{7}$ As tatuagens de palhaços e curingas são, entre os adolescentes, associadas à roubos e confrontos
com policiais. 
também o desamparo sentido por esses adolescentes na situação de internação, o que se evidenciou no desejo, verbalizado por eles, de que voltássemos para realizar outras atividades. Entretanto, o segundo grupo mostrou-se mais receoso com a proposta, como se qualquer atividade nova proporcionada por pessoas desconhecidas fosse colocar sua liberdade em risco.

Sobre a atividade de sensibilização, durante os sorteios das imagens, solicitou-se que os adolescentes se apresentassem. Após isso, cada um foi convidado a falar sobre o que tirou, deixando em aberto para que os outros também participassem. De início, em ambas as oficinas, os adolescentes permaneceram quietos, porém, no decorrer da atividade, essa atitude se transformou. A atividade proporcionou maior aproximação com os adolescentes, pois, ao final, praticamente todos, a partir dos próprios relatos e dos colegas, contribuíram para reflexões. Uma das questões levantadas foi que alguns gostos e/ou atitudes tendem a mudar com o tempo, enquanto outros permanecem, uma vez que são agradáveis e nos fazem bem.

Em relação a atividade "Viagem de Barco" em ambas as oficinas os adolescentes relataram a dificuldade de elencar dez itens importantes, disseram não possuir tudo isso para levar em uma viagem como essa. Alguns participantes não conseguiram elencar o número estipulado. Vale ressaltar que a maioria dos adolescentes escolheu a família ou um de seus membros (mãe, avó etc) como o "item" que permaneceria com eles no seu destino. Percebe-se que a figura do feminino está muito presente na fala dos adolescentes e, ao que parece, remete ao cuidado - que pode ser ou não oferecido dentro de seus núcleos familiares.

Fica clara a necessidade que estes adolescentes mostram, de ter alguém que olhe para eles, de figuras que possam ser utilizadas como referência para a construção de limites, da sensação de pertença, da sensação de ser cuidado. Mesmo com estruturas deficitárias, as figuras familiares aparecem como "pontos de retorno", o que evidencia a existência do sentimento de esperança nesses adolescentes, algo importante para reverter a tendência antissocial (WINNICOTT, 1956, 1961). Entretanto, infelizmente, há casos que essas estruturas não podem e/ou não poderão ser um ambiente facilitador, nesse caso, as instituições de socioeducação assumem um caráter ainda mais importante para esses adolescentes.

Além da família, outro aspecto citado por um adolescente de medida fechada foi a liberdade como algo para levar no barco, entretanto, na hora da escolha de um único item, optou pela família. Um outro adolescente, em medida aberta, escolheu como último item o Registro Geral (RG), escolha interpretada pelos mediadores como forma de assegurar uma identidade pessoal, englobando o sentido de ser cidadão, status muitas vezes negado ao adolescente em conflito com a lei. No fim do exercício, alguns adolescentes de ambas as medidas 
relataram a dificuldade de escolher algo para se desfazer, enquanto outros verbalizaram que, apesar da dificuldade, a família era algo certo a continuar.

Uma peculiaridade da oficina realizada com os adolescentes em internação foi a proposta de um "momento livre", no qual poderiam desenhar, escrever etc. Interessante notar a diferença de postura de todos os adolescentes nesse momento em comparação com o início das atividades, pois estavam mais espontâneos. Os mediadores circularam pela sala para observar o que estavam produzindo. Essa última atividade não foi aplicada na oficina em medida aberta.

Por fim, realizamos uma reflexão sobre as vivências, discutindo: as diferentes maneiras de se tomar uma decisão; as dificuldades de se fazer uma escolha; as consequências de cada escolha que empenhamos. Foi possível articular as falas e considerações dos adolescentes com as perspectivas da construção de projetos de vida, que englobam questões como o tipo de profissão de cada um gostaria de ter, a constituição da própria família e sonhos.

\section{Considerações Finais}

Assim, A exposição deste relato teve como intuito demostrar a importância da realização de trabalhos sobre projeto de vida com adolescentes em conflito com a lei, como forma de proporcionar a reflexão e estruturação de um projeto consistente que favoreça o afastamento das "zonas de perigo" em que eles se encontram. Sabe-se que, muitas vezes, os adolescentes em conflito com a lei causam incômodo nos ambientes em que se encontram inseridos, pois não se adequam às regras e acabam por transgredi-las, justamente por não sentirem-se integrados ao jogo social. Apesar disso, torna-se necessário perceber que a violência infanto-juvenil não pode ser resumida ao simples ato, sendo tratada apenas na via da repressão (seja ela policial ou médica), mas sim como uma questão social (LEVISKY, 1998) na qual se deve lançar um olhar multidisciplinar com o caráter preventivo e educacional.

Acreditamos que a periodicidade de trabalhos como este é fundamental para que os adolescentes possam pensar sobre si e sobre as suas escolhas. Ou seja, para efetivação desse tipo de proposta, é necessário que o tema da oficina seja um dos eixos do trabalho socioeducativo e não esteja restrito a alguns encontros esporádicos e que ocorram com maior frequência, em atividades dirigidas por agentes socioeducadoes internos ou colaboradores.

Por fim, entendemos que a profissão é um dos aspectos estruturantes da personalidade humana, que fundamenta a identidade vocacional e o sentido da vida (BOHOSLAVSKI, 2003). Assim, é importante possibilitar um espaço de acolhimento no qual o adolescente possa discutir e refletir sobre seus valores 
pessoais em relação à ocupação profissional de modo a identificar potencialidades que favoreçam tanto o seu desenvolvimento profissional quanto pessoal. Entrar em contato com as suas possibilidades e limites, enquanto pessoa humana, é fundamental para que os adolescentes em conflito com a lei possam realizar o desenho de um projeto de vida próprio, pessoal, que, em última análise é uma das direções das medidas socioeducativas.

\section{Referências}

ALEXANDRE, D. M. F.; BARCELOS, M. R. (2007). “Punição, assistencialismo e medida socioeducativa: uma abordagem prática institucional do IASES". In: BASTOS, R; ÂNGELO D.; COLNAGO, V. (orgs.). Adolescência, violência e a lei. Rio de Janeiro: Cia. De Freud; Vitória, ES: Escola Lacaniana de Psicanálise. p. 147-158.

AMORIM, S. M. F. Compreendendo o adolescente autor de ato infracionais. In: PAES, P. C. D.; AMORIM, S. M. F. (org.). Formação continuada de socioeducadores. Campo Grande, MS: Programa Escola de Conselhos, 2008. p. 35-38.

BLAY, E. Adolescência: Uma Questão de Classe Social e Gênero. In LEVISKY, D. L. (org.) Adolescência e Violência: Consequências da Realidade Brasileira. São Paulo: Casa do Psicólogo, 2000. p.35-39.

BOHOSLAVSKY, R. Orientação Vocacional: a estratégia clínica. Trad. Jose Maria Valeije Bojart. 11 ed. 2a tiragem. São Paulo: Martins Fontes, 2003.

BRASIL. Constituição (1988). Constituição da República Federativa do Brasil. Disponível em: $<$ http://www.planalto.gov.br/ccivil 03/constituicao/ConstituicaoCompilado.ht $\underline{\mathrm{m}}>$. Acesso em: 8 out. 2015.

. Estatuto da criança e do adolescente (1990). São Paulo: Conselho Estadual dos Direitos da Criança e do Adolescente (CONDECA); Secretaria de Estado da Justiça e da Defesa da Cidadania, 2012.

Parâmetros para formação do socioeducador: uma proposta inicial para reflexão e debate. Brasília: Secretaria Especial dos Direitos Humanos (SEDH), 2006. Disponível em: 
$<$ https://www.tjsc.jus.br/infjuv/documentos/midia/publicacoes/cartilhas/crianca eadolescente/Par\%C3\%A2metros\%20para\%20a\%20Forma\%C3\%A7\%C3\%A3o\% 20do\%20Socioeducador.\%20Uma\%20Proposta\%20Inicial\%20para\%20Reflex\%C 3\%A3o\%20\%20e\%20Debate.pdf>. Acesso em: 8 dez. 2015.

- Conselho Nacional dos Direitos da Criança e do Adolescente (CONANDA). Sistema Nacional de Atendimento Socioedacativo (SINASE). Brasília: CONANDA, 2006.

- Panorama Nacional: a execução das medidas socioeducativas de internação - Programa Justiça ao Jovem. Conselho Nacional de Justiça (CNJ), 2012.

Lei $\mathrm{n}^{\mathrm{o}}$ 12.594, de 18 de janeiro de 2012. Institui o Sistema Nacional de Atendimento Socioeducativo (SINASE), regulamenta a execução das medidas socioeducativas destinadas a adolescente que pratique ato infracional. Presidência da República, 2012. Disponível em: < http://www.planalto.gov.br/ccivil_03/_ato2011-2014/2012/lei/112594.htm>. Acesso em: 10 out. 2018.

Relatório da Infância e Juventude - Resolução nº 67/2011: Um olhar mais atento às unidades de internação e semiliberdade para adolescentes. 2 ed. 92. il. Brasília: Conselho Nacional do Ministério Público (CNMP), 2015. Disponível em: < http://www.cnmp.gov.br/portal/images/Um_Olhar_mais_Atento_09.06_WEB.p df>. Acesso em: 1 dez. 2015.

Plano Nacional de Atendimento Socioeducativo: Diretrizes e eixos operativos para o SINASE. Brasília: Secretaria de Direitos Humanos da Presidência da República, 2013. Disponível em: < http://www.mpgo.mp.br/portal/arquivos/2017/03/03/17_49_45_295_Plano_NAC IONAL_Socioeducativo.pdf $>$. Acesso em: 01 out. 2018.

CENTRO DE DEFESA DOS DIREITOS DA CRIANÇA E DO ADOLESCENTE (CEDEDICA). Orientação para implementação das medidas socioeducativas em meio aberto de Liberdade Assistida e Prestação de Serviços à Comunidade. Santo Ângelo RS. 2009. Disponível em: < http://cededica.org.br/z_novosite/downloads/manual_cededica.pdf $>$. Acesso em: 03 mar. 2017. 
DIAS, Elsa Oliveira. Unabomber: a violência do impotente. In Sobre a confiabilidade e outros estudos. São Paulo: DWW Editorial, 2011. p. 285-343.

FERREIRA, L. A. M. A educação nas legislações na área da infância e da juventude. In: . O Estatuto da Criança e do Adolescente e o professor: reflexões na sua formação e atuação. São Paulo: Cortez, 2008. p. 39-74.

FUNDAÇÃO CASA. Missão, visão $e$ valores. Disponível em: < http://www.fundacaocasa.sp.gov.br/View.aspx?title=miss\%C3\%A3ovis\%C3\%A3o-e-valores\&d=81>. Acesso em: 01 out. 2018.

\section{Disponível}

em:

$<$ http://www.fundacaocasa.sp.gov.br/View.aspx?title=miss \%C3\%A3ovis\%C3\%A3o-e-valores\&d=81>. Acesso em: 10 dez. 2015.

INSTITUTO LATINO AMERICANO DAS NAÇÕES UNIDAS PARA PREVENÇÃO DO DELITO - ILANUD. Guia Teórico e Prático de Medidas Socioeducativas. BRASIL: UNICEF, 2004.

LEVISKY, D. L. Adolescência e violência: a psicanálise na prática social. In: (org.). Adolescência pelos caminhos da violência: a psicanálise na prática social. São Paulo: Casa do Psicólogo, 1998. p. 21-43.

LEVISKY, D. L. Aspectos do Processo de Identificação do Adolescente na Sociedade Contemporânea e suas Relações com a Violência. In: (org.) Adolescência e Violência: Consequências da Realidade Brasileira. São Paulo: Casa do Psicólogo, 2000. p. 19-34.

LIBERATI, W. D. Comentários ao Estatuto da Criança e do Adolescente: 11ª edição, revista e ampliada, de acordo com a Lei 12.010, de 3.8.2009. ed. 11a. São Paulo: Malheiros Editores, 2010.

MAIA, M. V. C. M. e cols. "Crianças impossíveis" - quem as quer, quem se importa com elas?. Psicologia em Estudo, Maringá, v. 12, n. 2, p. 335-342, maio-ago/2007. 
MARIN, I. S. K. Sujeito, desamparo e violência. Revista Latino-americana de Psicopatologia Fundamental, v. 2, n. 3. 1998. Disponível em: $<$ https://www.psicopatologiafundamental.org/uploads/files/revistas/volume02/ n3/sujeito_desamparo_e_violencia.pdf>. Acesso em: 25 mar. 2016.

. De violência à violência fundamental. In: . Violências. São Paulo:

Escuta: Fapesp, 2002. cap. 2, p. 63-85.

MENDEZ, E. G. A Dimensão Política da Responsabilidade Penal dos Adolescentes na América Latina: notas para a construção de uma modesta utopia. Educação e Realidade, v. 33(2), jun/dez 2008. p. 15-36.

MORAIS, A. C; MALFITANO, A. P. S. Medidas socioeducativas em São Paulo: os serviços e os técnicos. Psicologia e Sociedade, Belo Horizonte, v. 26, n. 3, p. 613621, dez. 2014. Disponível em: $<$ http://www.scielo.br/scielo.php?script=sci_arttext\&pid=S010271822014000300010\&lng=pt\&nrm=iso>. Acesso em: 03 mar. 2017.

PLANO MUNICIPAL DE MEDIDAS SOCIOEDUCATIVA EM MEIO ABERTO. Araçatuba - $\quad$ SP. 2017. Disponível em: < http://www.tjsp.jus.br/Download/Corregedoria/pdf/InfanciaJuventude/Planos Municipais/ARA\%C3\%87ATUBA.pdf>. Acesso em: 05 mar. 2017.

SARAIVA, J. B. C. Desconstruindo o mito da impunidade: Um ensaio de Direito (Penal) Juvenil. Brasília: Universidade de Brasília, 2002.

J. B. C. Adolescente em conflito com a lei: da indiferença à proteção integral: uma abordagem sobre a responsabilidade penal juvenil. 3. ed. Rev. Atual. Porto Alegre: Livraria do Advogado Editora, 2009.

TAVARES, J. F. Comentários ao Estatuto da Criança e do Adolescente. Rio de Janeiro: Forense, 2012.

WINNICOTT, D. W. A tendência anti-social. 1956. In: - Privação e delinquência. 5. ed. São Paulo: Martins Fontes, 2012. cap. 14. p. 135-147. 
SANTOS, G.J.P.A; KOEHLER,S.M.F.; VILELA, J.S.. Socioeducação e Projeto de Vida: relato de oficinas com adolescentes em cumprimento de medida socioeducativa em meio aberto e fechado . R. Científica UBM - Barra Mansa (RJ),

ano XXIII, v. 20, n. 39, 2. Sem. 2018. Págs 132- 153

ISSN 1516-4071

WINNICOTT, D. W. (1961). Adolescência: Transpondo a Zona das Calmarias. In: A família e o desenvolvimento individual. 4. ed. São Paulo: Martins Fontes, 2011. cap. 10, p. 115-128. 